\title{
Sentidos da violência conjugal: análise do banco de dados de um serviço telefônico anônimo
}

I ${ }^{1}$ Concepcion Gandara Pazo, ${ }^{2}$ Adriana Cavalcanti de Aguiar |

Resumo: Este artigo visa a identificar e analisar, no banco de dados resultante dos registros de um serviço telefônico anônimo de apoio e orientação nas áreas de direitos e violência contra a mulher, a atribuição de significados de suas usuárias em relação às experiências de violência conjugal, à luz, principalmente, da literatura feminista brasileira contemporânea. Este artigo alinha-se a um grupo de pesquisadoras que focaram a atenção em descrever e refletir sobre as representações femininas acerca da violência, salientando a não-universalidade da experiência feminina diante das agressões, valorizando aspectos singulares dessas agredidas. Destacam-se, na análise, os sentidos dados pelas mulheres às prolongadas hesitações frente ao expresso desejo de se separarem de cônjuges violentos. Os resultados corroboram pesquisas precedentes relativas à complexidade $\mathrm{e}$ morbidade do fenômeno, como também apontam para a necessidade da interseção de campos de pesquisa visando à ampliação de seu entendimento e de intervenções mais eficazes.

Palavras-chave: violência contra a mulher; disquemulher; relações de gênero; sentidos da violência conjugal.
1 Médica homeopata e psicoterapeuta Doutoranda em Saúde Coletiva pelo Instituto de Medicina Social/UERJ (IMS/ UERJ). Endereço eletrônico: conchitapazo@oi.com.br

${ }^{2}$ Médica. Doutora em Educação (2000) pela Harvard University, professora do Instituto de Medicina Social (IMS), Pesquisadora IMS/UERJ e professora adjunta no mestrado profissional em Saúde da Família da Universidade Estácio de Sá (Unesa/RJ). Endereço eletrônico: adriana.aguiar@ post.harvard.edu

Recebido em: 10/12/2009. Aprovado em: 26/08/2010. 


\section{Introdução}

Violência contra a mulher, violência doméstica, violência de gênero, violência conjugal: muitas denominações ainda não superam o importante grau de invisibilidade do problema em nossa sociedade. Na prática, os termos citados são intercambiáveis e aplicados na análise da violência contra a mulher e da violência conjugal, esta última significando a violência nas relaçóes erótico-afetivas, amplamente denominada na literatura internacional como violência por parceiro íntimo. A falta de consenso conceitual ajuda pouco a delimitar espaços, relaçôes de causa e efeito e modalidades de ocorrência de violência nas relações íntimas, o que é agravado pela escassez de dados confiáveis que permitam delimitar e compreender melhor as dinâmicas subjacentes ao fenômeno da violência interpessoal no mundo privado.

O presente artigo irá apresentar, analisar e discutir dados oriundos de um serviço telefônico anônimo de atendimento nas áreas de direitos e violência contra a mulher, chamado de Disque-Mulher. Parte-se da premissa de que, em relação à violência (em geral) como problema de saúde pública, não basta quantificar mortos, feridos, vítimas e agressores. É necessário desenvolver uma compreensão que leve em conta "os sentidos da violência" (MINAYO, 2006, p. 112), ou seja, seu aspecto qualitativo.

Apesar de toda a dificuldade de obtenção de dados confiáveis a respeito da violência conjugal no Brasil, a semelhança dos números expostos em diversas pesquisas nacionais e internacionais deixa pouca margem de dúvida quanto à magnitude do problema e suas consequências para a sociedade.

Estudo analisando dados provenientes de serviços ambulatoriais de saúde estima que pelo menos 35\% das queixas de mulheres sejam associadas à violência conjugal (MINAYO, 2006). Segundo Minayo (2006), a violência mais comum que as mulheres sofrem não é o homicídio provocado pelo marido ou por desconhecidos, mas sim as lesões e traumas cotidianos consequentes das interaçôes conjugais conflitadas. Tal estimativa corrobora estudo da $\mathrm{OMS}^{1}$ realizado entre 2000 e 2003, que aponta para maior risco de depressão em mulheres com histórias de violência conjugal, tentativa de suicídio, distúrbios gastrointestinais, maior dificuldade de se protegerem das doenças sexualmente transmissíveis (inclusive a HIV/AIDS) e também de usarem regularmente métodos contraceptivos. 
Apesar dos limites da informação, parece haver certo consenso das pesquisas para o fato de que as mulheres são vítimas de uma específica violência, denominada de violência de gênero. $O$ conceito de gênero, entendido como construção social do masculino e do feminino e como categoria de análise das relações entre homens e mulheres é básico para se compreenderem as complexidades do fenômeno. Haveria uma violência perpetrada por parceiros, ou ex-parceiros íntimos, caracterizando-se como uma violência que ocorre nas relações eróticoafetivas, na intimidade de uma casa/família, que teria um delineamento baseado nas desigualdades de gênero.

Admitindo a face endêmica da conjugalidade violenta e a necessidade de um referencial teórico que permita a interpretação dos dados, apresentaremos, no corpo do artigo, uma discussão sobre a violência conjugal, principalmente na perspectiva do feminismo brasileiro, visando a contribuir para iluminar um fenômeno com contornos ainda pouco definidos. Várias pesquisadoras (SOARES, 1996; GREGORI, 1993, GROSSI, 1998; MACHADO; MAGALHĀES, 1999) salientaram a necessidade de aportar à análise dos dados quantitativos um arcabouço teórico que levasse em conta questôes do campo das subjetividades.

Os conflitos identitários de gênero podem estar na base do entendimento acerca das dificuldades das mulheres desvencilharem-se - por meio da separação ou de transformações nas relações de poder assimétricas presentes no casamento - de relaçôes conjugais violentas. Gregori (1993) e Machado e Magalhães (1999) compreendem a subjetividade feminina como sendo constituída diferentemente da masculina, e localizam o fulcro do problema nos conflitos consequentes à experiência cotidiana dessas diferenças entre os cônjuges. O "eu" psíquico sente e deseja, age e se interroga desde uma matriz de inteligibilidade que inclui sempre o que a cultura informa e oferece como vias de significação de si mesmo e do outro (BUTLER, 2003). Há, pois, um nível de apreciação do problema que perpassa questôes coletivas, genéricas, que serão atualizadas no que podemos chamar de um campo mais extenso - o das particularidades e singularidades dos cônjuges.

Voltaremos a esses temas no momento da discussão sobre o conteúdo dos relatos provenientes dos registros telefônicos do Disque-Mulher. 


\section{Uma estratégia para o enfrentamento da violência contra a mulher: a experiência da ONG Ser Mulher}

A ONG Ser Mulher - Centro de Estudos e de Ação da Mulher Rural e Urbana - construiu sua estratégia de enfrentamento da violência na cidade de Nova Friburgo, município com cerca de 180 mil habitantes (IBGE, PNAD, 2005), situado na região serrana do estado do Rio de Janeiro. A instituição foi criada em 1989 por um grupo de mulheres que se organizaram visando dar maior visibilidade às consequências das desigualdades de gênero, e teve como um dos primeiros eixos de ação a violência contra a mulher.

$\mathrm{O}$ projeto do serviço telefônico de orientação e apoio às mulheres nas áreas dos direitos e da violência, Disque-Mulher (DM), obteve, em 2001, apoio de uma agência financiadora internacional. $\mathrm{O}$ atendimento telefônico era realizado de $2 \mathrm{a}$ a 6 feira, das 10 horas às 18 horas. Havia um rodízio de plantões, no qual estagiárias de direito e psicologia e voluntárias das duas áreas se revezavam, ao longo dos anos. A coordenadora geral do serviço e uma advogada estavam sempre presentes.

Em 2004, a equipe coordenadora do DM (da qual uma das autoras do artigo fazia parte) introduziu uma nova metodologia de atendimento que, a princípio, não tinha o objetivo de ser traduzida na forma de uma pesquisa acadêmica. Foi realizada capacitação de todas as plantonistas do serviço, enfatizando que a escuta telefônica fosse mais livre e as orientações às usuárias, menos "prescritivas". Além disso, o registro escrito do diálogo telefônico deveria ser o mais fidedigno possível às falas das usuárias. Relativamente ao serviço, objetivava-se, com essas mudanças, ampliar o entendimento das dramáticas situações relatadas pelas suas usuárias e um melhor manejo dos telefonemas por parte das plantonistas. Foi a partir das supervisões semanais dos casos, realizadas pela equipe coordenadora, que à autora participante do serviço foram se impondo a riqueza da experiência vivida e a importância de registrá-la.

Salientamos que a apresentação dos dados provenientes dos registros dos telefonemas do DM, apesar das dificuldades metodológicas enfrentadas e que serão discutidas a seguir, orientam-se para a produção de informação qualificada. Vale ressaltar, porém, que os "sentidos da violência” para as mulheres que ligam para o DM não podem ser delineados de maneira precisa a partir dos registros. $\mathrm{O}$ 
que se obtém são flashes, vinhetas férteis de significados, sobre os quais refletiremos

a partir, principalmente, do referencial analítico apontado anteriormente.

O banco de dados que analisaremos compóe-se de 413 registros realizados entre janeiro de 2004 e outubro de 2006, após mudança na metodologia de escuta e registro dos atendimentos. Esses últimos passaram a ser manuscritos (sem a adoção de roteiro pré-estruturadoº ${ }^{2}$.

\section{Análise do banco de dados do DM}

Do total de 413 registros , 70\% das mulheres que ligaram têm entre entre 20 e 49 anos. 75\% das mulheres declaram-se casadas ou em união estável; 13\% são separadas ou divorciadas; e 12\% não informaram seu estado civil. A escolaridade apresentou os seguintes números: $17 \%$ não informaram, $70 \%$ têm ensino médio incompleto, $4 \%$ completo; $3 \%$ ensino superior incompleto, $6 \%$ completo. Quanto à profissão, a grande maioria definia-se por ocupações domésticas: bordadeira, faxineira, doméstica, costureira, aposentada. Não foi possível aferir quantas usuárias tinham trabalho remunerado.

Quanto ao motivo principal dos telefonemas, cabe uma reflexão. Em um mesmo telefonema a usuária pode abordar diversos aspectos de sua situação atribuindo-lhes diferentes pesos. Por exemplo, a usuária pode começar seu relato por uma violência sofrida recentemente (solicitando orientações para denunciar o agressor) e, ao longo da conversa, pedir orientaçóes acerca de seus direitos patrimoniais. Assim, a plantonista preenche o campo "assunto"3 com o que considera o motivo principal do telefonema. Ao situarmos o trabalho de coleta e registro de dados no campo das interpretações, é possível supor que, caso às usuárias fosse perguntado, mais de uma vez, o que as levou a telefonar, elas poderiam dar diferentes respostas num mesmo telefonema.

Em um número muito grande de telefonemas, nos quais o motivo principal assinalado girava em torno da violência, questões do direito de família também surgiram. Nesses casos, contamos como motivo principal a "busca por direitos" apenas quando o telefonema não fazia menção direta à violência.

A classificação das violências é complexa. Em muitos relatos a violência física mistura-se com a psicológica, obrigando o estabelecimento de prioridades na eleição da variável "motivo do telefonema". Assim, foram computados 
como violência psicológica os casos onde esse tipo era relatado exclusivamente. Procedeu-se da mesma forma com a violência sexual. Esta só foi computada como motivo principal quando surgia como sendo o fator que moveu a usuária a ligar, já que, em muitos telefonemas, as mulheres relatam situações de sexo forçado dentro do casamento. Cinco foram os principais motivos dos telefonemas, e estão representados abaixo no gráfico 1 :

\section{Gráfico 1. Principais motivos dos registros telefônicos do banco de dados}

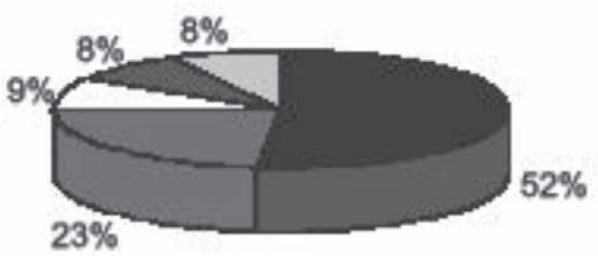

- vidència geral

abusca por direitos na área familiar 口 busca por direitos na área civil morientaçăo psicológica 口outros

Em 213 telefonemas (51,5\%), a violência foi o motivo principal das chamadas. Já em 134 (32,5\%), o motivo principal foi a busca de esclarecimentos no campo dos direitos, majoritariamente os familiares, com 97 (23,4\%) telefonemas envolvendo questões patrimoniais, guarda e pensão alimentícia dos filhos. Em 37 telefonemas (9\%), as usuárias buscavam orientaçōes para contendas com vizinhos e no trabalho.

Em 33 telefonemas (8\%), as usuárias procuraram orientação psicológica ou apoio para atravessarem momentos difíceis. Em 33 telefonemas (8\%), foram identificados os mais variados motivos que incluem: solicitação de emprego, denúncias de roubos e queixas acerca de mal atendimento em delegacias e hospitais.

Sumarizamos a seguir os tipos de violência identificados, salientando que nos deteremos apenas na análise da violência conjugal. $\mathrm{O}$ gráfico 2 explicita os números correspondentes: 


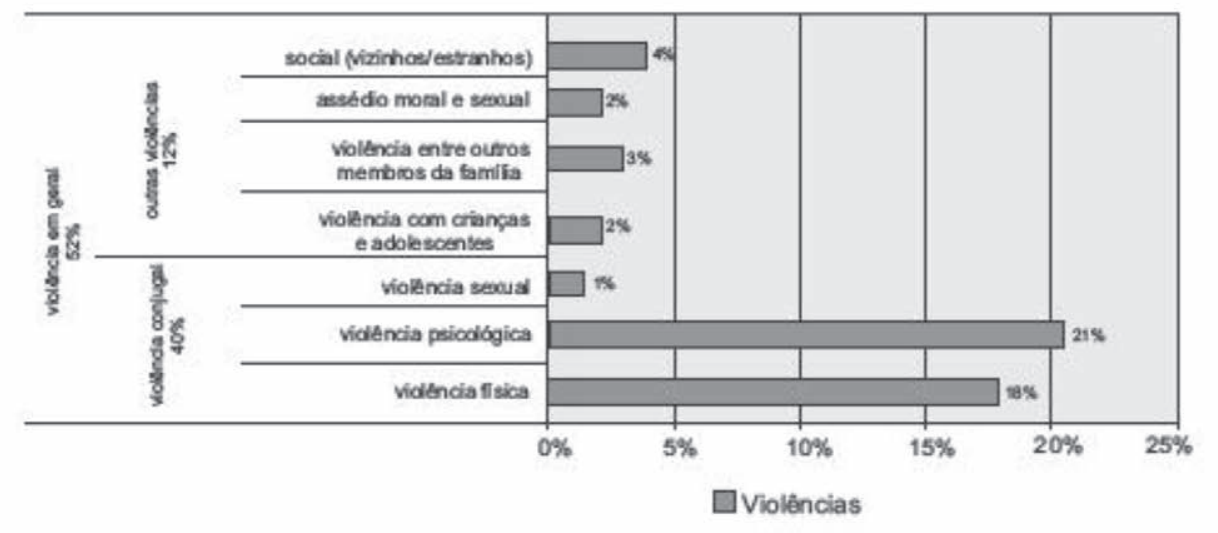

a) A violência conjugal perpetrada por maridos, ex-maridos, namorados e exnamorados aparece em 168 telefonemas, correspondendo a 40\% do total. Destacam-se do banco de dados 76 registros $(18,4 \%)$ de violência física e 85 registros $(20,6 \%)$ de violência psicológica, sendo 23 casos de ameaças de morte e 8 casos de expulsão de domicílio. Seis casos $(1,4 \%)$ tiveram como motivo a violência sexual (três praticados pelos cônjuges e três por excônjuges). $\mathrm{O}$ índice de violência sexual aumenta para 3,3\% se computados os números relativos aos praticados contra crianças e adolescentes (sete casos) ou por estranhos à mulher (um caso). Foi identificado um caso de violência entre um casal homossexual de homens.

b) Em 24 telefonemas (5,8\%), a violência intrafamiliar foi o motivo principal.

c) Em 18 telefonemas (4,3\%), violências praticadas por vizinhos, conhecidos distantes ou estranhos foram classificadas como violência social.

d) Em seis telefonemas (1,5\%), o motivo foi assédio moral e sexual em local de trabalho.

\section{Temas comumente associados à violência conjugal}

Dos 168 telefonemas motivados pela violência conjugal, em 97 (60\%) as usuárias percebem ou identificam alguma causa ou fator disruptor à violência sofrida. Desses, em 25 casos (15,5\%) as mulheres associam a violência à embriaguez do 
agressor. É comum a mulher expressar que "ele só bate quando bebe". Outros fatores associados incluem: a rejeição, por parte dos cônjuges violentos, da ideia de separação; divergências relacionadas à guarda e educação dos filhos, rejeição do cônjuge à gravidez, interdições a práticas religiosas, restrições à liberdade de ir e vir.

As usuárias, muitas vezes, culpam os homens de causar os conflitos e violências domésticas por conta do desregramento, da inconsequência, pelo descontrole, pelo desejo que têm de controlá-las. De modo geral, devido às características dos registros, não houve espaço para percepção de como se estabelecem as comunicações, as interações simbólicas entre o casal, já que o que aparece é uma descrição do cônjuge em posição antagônica à mulher.

Eu trabalho o dia inteiro e ele só sabe me xingar de preta, piranha e vagabunda. Eu que boto comida em casa, porque costuro em casa, faço todo o serviço e só levo na cara. Eu quero me separar. Não aguento mais. Não tinha café hoje e então ele saiu chutando tudo. Diz que eu não sirvo prá nada... eu pensei ir prá casa da minha mãe, mas vou acabar perdendo meus direitos (não informou idade).

É comum o homem ser retratado como um estorvo, alguém alheio, estranho à história da vida da mulher que liga para o DM. Gregori (1993) alerta para uma tendência observada em mulheres, por ela entrevistadas, de "criarem uma espécie de exterioridade na construção da imagem desses homens” (p. 152). Em que medida a manutenção dessa "exterioridade do homem" não estaria dificultando a implicação das mulheres nos processos conflituosos por elas vividos e retardando rupturas, é uma questão em aberto. Essa exterioridade se expressa muitas vezes como o "mal" colocado fora de si, contrastando com o virtuosismo de quem "só trabalha e bota comida dentro de casa". O casal vive posições polarizadas e estanques, em que a mulher, ao não entender (ou não explicitar) os motivos da agressividade percebida no cônjuge, constrói a ideia do outro como alguém inapreensível, inalcançável e, portanto, impedido de mudar.

As dificuldades em promover transformações nas relações de poder dentro da relação conjugal não têm apenas uma face privada, cristalizada em posições estanques como acima mencionadas. A violência conjugal surge através do relato de diversas ações de busca de assistência nas áreas jurídica e de segurança, que, nas palavras das usuárias, "não deram em nada", apontando para a influência do precário funcionamento do aparato do Estado, acionado para assistir e legislar contenciosos do mundo privado, o que dificulta sobremaneira a transformação das situações de violência. Ao não favorecer, de maneira equânime pelo menos, as 
necessárias transformações nas relações conjugais violentas com ações de âmbito estrutural (dirimir a desigualdade, promover a universalidade dos direitos, etc.) e contextual (garantia de assistência jurídica, de segurança pública e de saúde), o Estado também contribui com a perpetuação de relaçôes de gênero desiguais. As ações que "não deram em nada" são recorrentemente associadas a uma não resposta do mundo público ao apelo por soluçôes que visam à possibilidade de separações conjugais ou mediações dos conflitos que cessem as recorrentes situações de violência.

Embora os registros não tenham sido realizados com o foco em nenhuma variável específica, pesquisamos como são expressas nesses 168 registros, as experiências das mulheres relativas ao desejo de separarem-se das relações violentas. A literatura internacional aborda esse fenômeno denominando-o de "process of leaving" (ANDERSON; SAUNDERS, 2003; DAVIES et al., 2009). Sendo assim, a escolha da variável "separação conjugal e impasses", tendo como parâmetro a literatura consultada, objetiva analisar os sentidos dados pelas mulheres à violência sofrida e identificar os motivos alegados para as dificuldades sentidas em transformá-la. Estamos cientes dos limites do material obtido nos registros. Mesmo assim, acreditamos que a partir dele é possível avançar na busca de uma espécie de tipificação das dinâmicas individuais e interrelacionais de processos de separação presentes nos relatos, sem absolutamente apostarmos no esgotamento da apresentação dessas possibilidades, haja vista, como acima exposto, a importância dos elementos socioculturais na obstrução dos processos de transformações das relações violentas. Mesmo com diversas dificuldades, algumas adiante expostas, estudos apontam que mulheres que vivem relações conjugais violentas costumam se separar mais cedo do que mulheres que se separam em outra conjuntura (LOGAN et al., 2008).

\section{Pressupostos da violência conjugal}

$\mathrm{O}$ paradoxo que articula violência e relação afetivo-conjugal intrigou muitas pesquisadoras do campo da antropologia, e foram desenvolvidas várias linhas de indagação para explicá-lo. Num primeiro momento, os estudos feministas relacionaram as causas da violência contra a mulher com a ideologia da dominação masculina, formulada de diferentes formas por vários autores tais quais Chauí (1985), Bourdieu (1999), Saffiotti e Almeida (1995). 
Gregori (1993) estabeleceu um divisor de águas nos estudos feministas brasileiros sobre a violência afetivo-conjugal quando chamou a atenção para os perigos da simplificação da análise que privilegiava o enfoque no "processo de vitimização da mulher". A autora entende que, ao insistirem em colocar a mulher numa posição reiterada de vítima frente ao homem agressor, militantes e acadêmicas estariam reforçando estereótipos de fragilidade e incompetência, contribuindo para manter a situação opressiva vivida por grande parte das mulheres. Vista a princípio como uma inflexão que poderia enfraquecer as conquistas do movimento (já que potencialmente também responsabilizava a mulher pela violência), a corrente de estudos que se seguiu alinhou várias autoras (GROSSI, 1998; SOARES, 1996; MACHADO; MAGALHÃES, 1999) e complexificou a abordagem, convidando outras disciplinas, como a psicologia e a psicanálise, para o diálogo com as ciências sociais.

A violência pode ter significados distintos para as mulheres. Para Gregori (1993), a quebra de um pacto de reciprocidade estabelecido entre o casal (formatador de uma ordem e de um sentido) é que ensejaria o ato violento, numa tentativa desastrada de reconstituir a antiga ordem. Apreender as ambiguidades e tensões nas relações entre os papéis de gênero "permite entender que os padrōes distintos de comportamentos instituídos para homens e mulheres são atualizados em relações interpessoais, ou melhor, entram numa operação combinatória particular em cada relação de violência considerada” (1993, p. 146). Como exemplo da ambiguidade de sentimentos que o paradoxo entre violência e afetividade suscita, apresentamos um fragmento retirado dos registros telefônicos:

Estou me sentindo confusa. Meu irmão pede uma decisão. Ele acha que eu devo me separar de meu marido, mas ele não entende que eu gosto dele. Apesar de tantas feridas há amor entre nós dois. Quero me tratar, sair dessa vida. [...] Meu marido me agride e está agredindo minha filha de 13 anos de um tempo pra cá. Gostaria de um atendimento psicológico prá nós duas. Mas gostaria que vocês chamassem ele para ele também ir a um psicólogo. (46 anos).

Mesmo em relações conjugais nas quais não há violência explícita, é comum observar-se a dominação da mulher, exercida de maneira sutil. No entanto, as dualidades (ativo-passivo, algoz-vítima, autonomia-heteronomia) que marcaram os estudos de gênero não dão conta dos diversos sentidos em jogo nas interaçôes conjugais. A agressão tem múltiplas motivações e manifestaçōes e ocorre em determinados contextos com diferentes significados. 


\section{Dilemas e sentidos no processo de}

separação das relações conjugais violentas

Em um número expressivo, as usuárias do DM problematizam o tema da separação conjugal, em torno do qual surgem dúvidas, sentimentos de impotência, medos e raivas. Em aproximadamente um terço dos 413 registros telefônicos (127 casos), o tema da separação emergiu, e dentre esses, 105 (82,7\%) as mulheres associaram-no à violência conjugal. A maior parte dos registros (22) em que o tema da separação emerge sem menção à violência versa sobre dúvidas quanto aos direitos adquiridos com o casamento.

No universo de 168 casos de relatos de violência conjugal, em 105 (63,2\%) as usuárias referem o desejo, a decisão ou o impasse de se separarem. Dentre esses, 44 casos (42\%) expressam motivos específicos para prolongados períodos de hesitação frente ao declarado desejo de separação. Em 48 relatos, as usuárias já estão separadas (vivendo ou não sob o mesmo teto), e dentre esses, 26 mulheres relataram perseguições e ameaças dos ex-cônjuges. Essa taxa parece corroborar o que pesquisas nacionais e internacionais (MACHADO; MAGALHÃES, 1999; FLEURY et al, 2009; DAVIES et al., 2008) vêm apontando: que a separação não é, absolutamente, garantia de fim da violência. Pelo contrário, muitas vezes torna-se o gatilho para violências mais graves e/ou frequentes.

Em dezoito relatos (dentre os 44 que expressam o desejo de separação), o motivo alegado para impasses frente ao desejo de separação poderia ser atribuído a explícitos constrangimentos financeiros e/ou às incertezas quanto à garantia de direitos à moradia, guarda e pensão alimentícia da mulher e dos filhos. Como por exemplo:

Meu marido bebe e quando chega em casa me perturba com suas palavras e grosserias, me humilha, me agride e me aborrece muito. Sou casada há 39 anos e minha casa foi construída no terreno do pai dele, porém com a ajuda em dinheiro dos meus filhos. [...] Minha filha solteira [...] é que faz as despesas da casa, inclusive de meus remédios, ( ... ). Quando eu falo em me separar ele responde: 'os incomodados que se mudem'. Não tenho para onde ir e não quero mais viver com ele (60 anos).

Machado e Magalhães (1999), ao descreverem a tensão vivida por uma mulher em situação de violência em torno de seu direito à casa, demonstram como esta se associa facilmente a noçôes de identidade, traduzindo o sentimento que alimentaria a contenda, como se "ser alguém significa[sse] ter o próprio lugar” (p.191, grifo das autoras). 
Vinte e seis registros contêm elementos ilustrativos de impasse além do constrangimento econômico. Sua análise temática inclui cinco ênfases, ou núcleos de significado, que podem estar presentes na narrativa de uma mesma usuária e poderiam ser aproximadas do que a literatura internacional nomeia como "experiência de satisfação" e "grau elevado de investimento" na relação, apontandoos como variáveis presentes nos relatos de mulheres que experimentam relações conjugais violentas ao justificarem as dificuldades sentidas em conseguirem se separar (LOGAN at al., 2008; ROBERTS et al., 2008):

a) apresentam ambiguidade em relação ao que sentem pelo cônjuge:

Eu vivo com um homem há 11 anos [...] Ele já pediu a separação e já voltamos. Peguei uma carteira de Viagra no bolso dele. Coloquei ele na parede e ele disse que tomou o remédio por brincadeira.[...] Agora posso passar nua na frente dele, ele é indiferente. Eu sou a mulher da vida dele, eu nasci pra cuidar dele. A gente tinha uma relação sexual normal, e agora ele está desde segunda-feira dormindo separado. Eu gosto dele [...] Ele me agride por causa do meu ciúme. Mas se eu me separar dele agora, vou me separar odiando. Estou com dúvidas se quero me separar. Meu marido é $80 \%$ bom. Pedi a Deus uma prova se ele estava me traindo. Acho que o Viagra que encontrei é a resposta. Mas eu acho que eu deveria deixar isso pra lá, meu marido e eu já nos separamos outras vezes. Ele diz que se não me amasse não ficaria comigo (51 anos).

Machado e Magalhães (1999) analisam a especificidade dos casos em que as mulheres declaram-se envolvidas amorosamente com os agressores, apesar de viverem situações violentas prolongadas. Questionam se as mulheres se enredariam nessas relações por necessitarem de reconhecimento através do olhar masculino, "que as espelha" (p.223). A esperança de que o homem deixasse de agredir corresponderia à esperança de que ele lhe devolvesse a imagem de mulher desejada e "de mulher maternal capaz de gerir as emoções no interior das relações conjugais e familiares” (p. 224). A frase citada pela usuária corrobora essa linha de interpretação: "eu sou a mulher da vida dele, eu nasci para cuidar dele". Seria uma espécie de codependência, em que a mulher encontra sua identidade preenchendo supostas necessidades do outro. São parceiros que, "enlaçados por rituais privados que se repetem cotidianamente" (GREGORI, 1993, p. 183), rotinizam a violência. Acreditamos que essa codependência pode ser uma possibilidade de interpretação a ser melhor investigada, principalmente nos casos em que coexistem expressões de amor e ódio entre o casal.

b) acreditam que têm culpa pelas as agressões do marido:

[A usuária informa que] tem comportamento agressivo com o marido. Ele fala que ela é maluca. Ele, há cinco anos, fica xingando ela. [...]. "A culpa é minha, se eu me 
separar dele ele vai reunir as famílias, ele é uma pessoa de ótimo relacionamento com

várias pessoas". Ela sempre acha que vai tudo melhorar. Sente a auto-estima baixa e tem vontade de procurar um psiquiatra. (34 anos).

c) ainda acreditam no cônjuge ou nutrem compaixão:

Já tem um ano que estamos separados dentro da mesma casa [...]. Eu tenho medo de continuar com a separação porque estou adotando minha filha. Já fiz quatro boletins de ocorrência e já fui chamada uma vez, mas retirei as queixas porque ele ficava bonzinho e eu acreditava que ele ia mudar. (40 anos).

Gregori (1993) aponta como a vítima coopera na produção da violência quando atua como um não sujeito: "isto é, ela ajuda a criar aquele lugar no qual o prazer, a proteção ou o amparo se realizam desde que se ponha como vítima. Esse é o 'buraco negro' da violência contra a mulher: são situações em que a mulher se produz -não apenas é produzida- como não sujeito" (p. 184).

Escaparia ao escopo deste artigo um aprofundamento do que Gregori (1993) chama de "buraco negro" da violência contra a mulher, mas é imprescindível que o abordemos tangencialmente, pois ele se conecta com o que a seguir discutiremos sobre os efeitos do medo nas mulheres em relação a seus agressores. A autora, ao utilizar-se desta metáfora astronômica, refere-se a uma condição sociocultural da constituição da identidade das mulheres que as predispõem a uma subjetividade heterônoma, tal qual descrita por Chauí (1985). A heteronomia resultaria de uma constituição da subjetividade realizada a expensas do outro ou abrindo mão de importantes aspectos de si mesma. As relações violentas íntimas emergeriam, portanto, de relações de gênero coercitivas de poder e controle (DAVIES et. al., 2009) reduzindo a autonomia das mulheres e, segundo Chauí (1985: p. 36), sua liberdade, entendida como "capacidade de autodeterminação para pensar, querer, sentir e agir". A ideia de não sujeito não deve ser pensada de forma radical, mas entendida como constrangimento da potencialidade inerente a todo ser humano de tornar-se ele mesmo, o que só ocorre dentro de condições minimamente razoáveis de liberdade. O não sujeito seria constituído a partir de uma inibição reiterada de atos, pensamentos e sentimentos, levando a mulher, no caso, a depender de mudanças do outro para que então pudesse alçar à liberdade de si. Essa poderia, pois, ser uma trajetória explicativa para a hesitação prolongada frente ao desejo de separação.

d) resistem em denunciar e/ou retiram as queixas demonstrando dúvidas:

Uma vez eu liguei para aí e fui encaminhada a DP, fiz corpo de delito [...]. Na ocasião tinha perdido bebês gêmeos, pois estava grávida e isto ocorreu devido aos espancamen- 
tos. [...] quando recebi a intimação para comparecer à audiência, retirei a queixa. Ele foi se tratar e nós voltamos a nos relacionar. Fiquei grávida novamente e entramos para os “Casados para sempre”. Aí ele voltou a beber e o aluguel está atrasado. No sábado ele me deu dois socos nas costas. Fui para a casa da minha mãe. Ele disse que se eu não voltar ele vai queimar tudo o que é meu. [...] (40 anos; ensino superior completo).

Apelar para os "Casados para sempre", na esperança de instituir comportamentos e condutas esperadas para um pai de família, pode significar a atribuição a uma instância externa o papel de legitimador de pactos a serem renegociados na relação a dois.

e) sentem medo da reação do cônjuge

Há quinze anos sou casada com um homem e ele voltou a beber, me ameaçar, me bater, [...] Ele tem uma arma e me ameaça. Tenho muito medo da morte. Não consigo dormir e trabalho o dia todo [...]. Ele já bateu no meu filho e eu dei queixa na DP, isso tem um ano [...] (33 anos).

Meu marido me bate sem deixar marcas e eu sofro também violência sexual, mas ninguém sabe, porque eu fico quieta. Nós vivemos juntos durante quatro anos e ficamos separados durante cinco anos, agora faz um ano e pouco que voltamos. Eu quero sair de casa, tenho condições de me manter sozinha, tenho o meu trabalho, mas ele não quer deixar eu ir e fala que se eu sair me mata. [...]. Eu vivo à base de calmantes, ele diz que é safadeza[...] Ele me bateu e até me enforcou, mas não deixa marcas. Há cinco anos atrás eu fui na delegacia e não adiantou nada, (30 anos).

O medo é comum nos relatos das mulheres (TAFT et al., 2009a; TAFT et al., 2009b), agindo como potencial nutriente da paralisia ante a situaçõeslimite. O medo vai tomando conta da mulher, motivando-a a desenvolver ações calculadas a partir de possíveis atitudes agressivas do cônjuge, num processo que sugere um "apagamento de si”. Falas de mulheres em psicoterapia (PAZO, 2007) e entrevistas prolongadas (MACHADO; MAGALHÃES, 1999) corroboram esse fenômeno que, conforme estamos defendendo, parece ter dupla origem: pode decorrer do trauma (concebendo as reiteradas situações de violência ou intimidação experimentadas) ou da tendência culturalmente construída de uma certa constituição identitária de gênero que faz com que as mulheres tendam a abrir mão de si, de uma identidade mais autônoma em nome do todo familiar.

Apesar da evidência da forte influência do medo nas atitudes de aparente complacência da mulher com as agressōes recebidas, a literatura feminista não aprofunda a investigação acerca desse sentimento. É possível que, ao perceber a necessidade de superar a interpretação baseada na dicotomia vítima-algoz, as 
autoras tenham subestimado as consequências do medo. Assim, recorreremos aos

estudos no campo da psicologia sobre o trauma, buscando ampliar o entendimento da dinâmica do medo em relações conjugais violentas de longa duração. A variável da intenção do agressor, ou melhor, a percepção das mulheres sobre essa intenção, aparece como central nessa abordagem. Nos relatos analisados, é comum as mulheres narrarem episódios em que é evidente para elas o desejo do homem em machucá-las, calá-las e destruí-las.

Essa percepção sobre a intenção e a vivência frequente das situações de violência aproximam essas mulheres de experiências compatíveis com o diagnóstico de trauma. Rovinski (2004), analisando a trajetória do conceito de trauma pelo Manual Diagnóstico e Estatístico de Transtornos Mentais da Associação de Psiquiatria Americana (DSM), demonstra o refinamento e a abrangência que foi tomando o conceito de transtorno de estresse póstraumático (TEPT). Hoje, aparece como fundamental no DSM, quanto à caracterização de um trauma, que: "o evento traumático seja ameaçador à vida ou à integridade física da própria pessoa e que a resposta a este evento envolva intenso medo, impotência ou horror." (ROVINSKI, 2004, p. 50). Estudos internacionais relacionam a sintomatologia do TEPT $^{5}$ a histórias de violência conjugal severa e frequente (TAFT et al, 2009a; TAFT et al., 2009b).

Em que medida as usuárias do DM vivem quadros de TEPT, não se pode afirmar. Indícios de sintomatologia psicológica e física consequentes à longa permanência em casamentos violentos, são comumente comentados nos telefonemas, como, por exemplo, o uso de calmantes, emagrecimento, queixas de insônia e cefaleias. É bastante razoável, portanto, interpretar os possíveis efeitos da violência conjugal, pela sua repetição, como trauma psíquico de intensidade moderada ou grave, sem que estejamos aqui alinhando-nos a uma postura medicalizante de problemas que, conforme acima assinalados, são de natureza política e sociocultural.

O desejo de separação não foi sempre expresso de modo hesitante. Em 13 casos as usuárias expressaram-no, demandando compreender quais sanções incidirão sobre o cônjuge com a abertura do processo de separação e/ou quais os procedimentos podem agilizar a separação.

Eu liguei há algum tempo, mas você disse que eu tinha que ter certeza da separação. Agora eu tenho. Ele está mais agressivo e está ameaçando meu filho... Moro com ele há um ano e pouco... Ele ficava agressivo só quando bebia, agora não, mesmo sem 
beber ele é agressivo. Dei uma chance para ele, mas ele não mudou. Agora eu não quero mais. Onde eu preciso ir? Não quero cadeia não, quero me separar com todos os meus direitos. (35 anos).

Em 48 dos 168 casos de violência conjugal analisados, as mulheres estavam atravessando processos de separação. Algumas delas haviam saído de casa, ou o agressor havia saído, mas, eventualmente, ainda demonstravam dúvidas quanto aos direitos. Em 26 casos, as mulheres, apesar de separadas, relatam perseguições e ameaças.

É separada há algum tempo, só que o marido não aceita e está ameaçando o filho de 9 anos...No último final de semana ele a seguiu do barzinho até em casa e no domingo não permitiu que ela saísse para almoçar. Ficou apertando a campainha durante um longo tempo e ela ligou para a polícia... Já foi ao conselho tutelar que não fez nada. Já teve uma audiência no juizado especial criminal que não deu em nada. Eu não agüento mais, são dois anos de perturbação [...] (48 anos).

Nesses casos, a separação não foi suficiente para interromper um modelo de vínculo conjugal abusivo que provavelmente foi a própria causa da separação. Machado e Magalhães (1999, p. 212), analisando entrevistas com homens agressores e perseguidores de mulheres que decidiram separar-se à revelia, observaram "um obsessivo desejo por controle", além de precária elaboração em relação às suas atitudes violentas. Estudos internacionais apontam que restabelecer o controle é frequentemente o motivo por trás das violências praticadas pelos homens contra suas parceiras (FLEURY et al., 2000; DAVIES et al., 2009; ANDERSON; SAUNDERS, 2003).

Dirigindo-nos agora para as considerações finais deste artigo, gostaríamos de ressaltar a importância das pesquisas nas áreas de violência conjugal levarem em conta a qualificação da informação advinda da observação de características subjetivas dos cônjuges envolvidos no engendramento e na manutenção de suas relações violentas. Os empecilhos metodológicos enfrentados pelo banco de dados analisado neste artigo impedem o aprofundamento necessário e provocam o desafio para pesquisas futuras.

\section{Consideraçôes finais}

Pesquisas que abordem de maneira mais minuciosa os sentidos dados tanto por mulheres como homens em situação de violência conjugal poderão revelar de maneira mais esclarecedora o que a análise qualitativa desses relatos e suas 
interpretações sugeriram neste artigo, ou seja, que no fenômeno conflitivo conjugal entrelaçam-se os aspectos coletivos e individuais de cada um dos envolvidos. É provável que estejam localizadas na interseção dos estudos das construçôes identitárias de gênero desde uma perspectiva mais psicológica (que atente para aspectos do idiossincrático) e outra mais cultural-antropológica (que atente mais para a construção dos estereótipos culturais das identidades de gênero) as possibilidades interpretativas mais promissoras para esse fenômeno que vem desafiando campos tão diversos da pesquisa acadêmica.

Ao privilegiarmos em nossa análise dos registros do DM as diversas formas de disposições e de emoções relativas à violência sofrida pelas usuárias, alinhamonos a uma perspectiva de análise da violência conjugal que aposta na importância do entendimento das emocionalidades (coragem, angústia, medo, raiva, ódio, amor, apego, etc.) presentes nos discursos sobre violência e na distribuição destas em torno das categorias de gênero (DAS, 2008).

Estudos mais recentes (DAS, 2007; 2008), além de interrelacionar subjetividade, gênero e violência, vêm apontando para a necessidade de pesquisas em torno de como os afetos, acima mencionados como emocionalidades, podem ajudar a entender o que consideram a característica central da violência: ao mesmo tempo que é um fenômeno costumaz à vida cotidiana, constitui-se também como fator disruptivo da vida ordinária. Assim vista, a violência continua desafiando profundamente as pesquisas e, segundo Das (2007; 2008), beneficia-se de abordagens que privilegiem o estabelecimento de temas, mesmo que de maneira não solidamente estabelecidos, na análise de material etnográfico (geralmente narrativas de mulheres e homens em situação de violência).

Apontamos a prevalência de seis núcleos de significados ou ênfases na análise dos registros do DM em relação às experiências das usuárias nos processos de separação/transformação das relações violentas. $\mathrm{O}$ constrangimento econômico expresso de diversas formas pelas usuárias do DM, somado à insuficiência das ações do Estado na promoção de equidade social e de gênero, faz parte de um contexto social inalienável das análises das relações conjugais violentas e compõe a rede de fatores característica do "process of leaving".

Desde as duas últimas décadas, pesquisadores ampliaram a discussão da violência contra a mulher para além do estereótipo binário vítima-algoz. A polissemia de sentidos (SOARES, 1996) e a profusão de interseções entre categorias (gênero, 
idade, cor, classe, religião, escolaridade), disposições, afetos e conjuntura social delimitam instavelmente seus contornos. A árdua tarefa de ordenação e coalescência temática entre os vários estudos que têm como perspectiva a busca de significados nos discursos sobre violência pode ter como efeito um estímulo à transformação das relações entre os sexos, e também intervençôes políticas mais eficazes ${ }^{6}$.

\section{Referências}

ANDERSON, D.K.; SAUNDERS, D.G. Leaving an abusive partner: an empirical review of predictors, the process of leaving and psychological well-being. Trauma, Violence \& Abuse, v. 4, p. 163-191, 2003.

BUTLER, J. Problemas de gênero: feminismo e subversão da identidade. Rio de Janeiro: Civilização Brasileira, 2003. 236 p.

BOURDIEU, P. A dominação masculina. Rio de Janeiro: Bertrand Brasil, 1999. 169 p.

CHAUÍ, M. Participando do debate sobre mulher e violência. In: CARDOSO, R.; CHAUÍ, M.; PAOLI, M.C. (Orgs.). SOS-Mulher. Perspectivas antropológicas da mulher. Rio de Janeiro: Zahar, v.4, p. 23-62, 1985.

DAS, V. Violence, gender and subjectivity. Annual Review of Anthropology. v. 37, p. 283-99, 2008.

. Life and Words: Violence and the Descent into the Ordinary. Berkeley: Univ. Calif. Press, 2007. $281 \mathrm{p}$.

DAVIES, L.; FORD-GILBOE, M.; HAMMERTON, J. Gender inequality and patterns of abuse post leaving. Journal of Familiar Violence, v. 24, p. 27-39, 2009.

FLEURY, R.E., SULLIVAN, C.M, BYBEE, D.I. When ending the relationship does not end the violence: women's experiences of violence by former partners. Violence against women, v.6, p. 1363-1383, 2000.

GREGORI, M.F. Cenas e queixas. Um estudo sobre mulheres, relaçôes violentas e práticas feministas. São Paulo: Editora Paz e Terra, 1993. 218 p.

GROSSI, M.P. Rimando amor e dor: reflexōes sobre violência no vínculo afetivoconjugal. In: PEDRO, J.M.; GROSSI, M.P. (Orgs). Masculino, feminino, plural: gênero na interdisciplinaridade. Florianópolis: Mulheres, p. 293-313, 1998.

IBGE. Diretoria de Pesquisa. Coordenação de População e Indicadores Sociais, Estatísticos de Registro civil, 2005. PNAD - 2005 - V. 26 - Brasil.

LOGAN, T.K. et al. Factors associated with separation and ongoing violence among women with civil protective orders. Journal of Familiar Violence, v.23, p.377-385, 2008. 
MACHADO, L.Z.; MAGALHÃES, M.T.B. Violência conjugal: os espelhos e as marcas. In: SUÁREZ, M. e BANDEIRA, L. (Orgs). Violência, Gênero e Crime no Distrito Federal. Brasília: Paralelo 15, Editora Universidade de Brasília, p.173-237, 1999.

MINAYO, M.C.S. Violência e saúde. Rio de Janeiro: Editora Fiocruz, 2006. 132 p.

ORGANIZAÇÃO MUNDIAL DE SAÚDE. The WHO Multi-Country Study on Women's Health and Domestic Violence Against Women. Disponível em: <http://www.who.int/ violence_injure_prevention/>. Acesso em: $10 \mathrm{dez} .2006$.

PAZO, C.G. Enfrentando a violência contra a mulher: uma experiência pioneira no interior do Estado do Rio de Janeiro. 2007. 129 p. Dissertação (Mestrado) - Instituto de Medicina Social, Universidade do Estado do Rio de Janeiro, Rio de Janeiro, 2007.

ROBERTS, J.C., WOLFER, L.; MELE, M. Why victims of intimate partner violence withdraw protection orders. Journal of Familiar Violence, v. 23, p. 369-375, 2008.

ROVINSKI, S.L.R. Dano psíquico em mulheres vitimas de violência. Rio de Janeiro: Lúmen, 2004. $271 \mathrm{p}$.

SAFFIOTTI, H.I.B.; ALMEIDA, S.S. Violência de gênero. Poder e impotência. Rio de Janeiro: Revinter, 1995. 218 p.

SOARES, B.M. Delegacia de atendimento à mulher: questão de gênero, número e grau. In:

SOARES, L. E. (org.) Violência e politica no Rio de Janeiro. Rio de Janeiro: ISER: RelumeDumará, p.107-123, 1996.

TAFT, C.T. et al. An investigation of posttraumatic stress disorder and depressive symptomatology among female victims of interpersonal trauma. Journal of Familiar Violence, v. 24, p. 407-415, 2009 (a).

TAFT, C.T.; MANSON, C.M.; SCHUMAN, J.A. et al. Posttraumatic stress disorder symptoms, relationship adjustment and relationship aggresion in a sample of female flood victims. Journal of Familiar Violence, v. 24, p. 389-396, 2009 (b).

\section{Notas}

${ }^{1}$ The World Health Organization Multi-Country Study on Women's Health and Domestic Violence Against Women é uma ampla pesquisa que consiste num inquérito de prevalência da violência praticada por parceiro íntimo, das repercussóes físicas, psicológicas, sexuais e reprodutivas na saúde da mulher e de suas possíveis formas de enfrentamento.

${ }^{2}$ Estamos cientes de que, por mais que a orientação dada às plantonistas seja a de ater-se ao máximo à descrição das falas, a intermediação entre o que é dito e o que é escutado implica num processo inerente de interpretação. Significa, entre outras coisas, que a riqueza de detalhes escritos varia de plantonista para plantonista, gerando uma heterogeneidade intrínseca ao conjunto de registros. 
${ }^{3}$ Uma folha de atendimento preenchida após o telefonema era composta por diversos campos como "assunto", "tipo de violência", "dados pessoais", etc.

${ }^{4}$ Grupos ligados a igrejas evangélicas que "têm o objetivo de levar os casais a redescobrir princípios bíblicos que os ajudem a fortalecer e curar seus casamentos" (www.jesusvem.com.br).

${ }^{5}$ Os sintomas físicos do TEPT são os visíveis hematomas, cortes, estresse crônico com dores de cabeça, alterações hormonais/menstruais, fadiga, etc. Os sintomas psicológicos são próprios às experiências traumáticas de choque: negação, recolhimento, confusão, entorpecimento e medo; seguidos de depressão, desesperança, baixa auto-estima e negação (ROVINSKI, 2004, p. 78).

${ }^{6}$ C.G. Pazo participou da coleta e da análise de dados e da redação do artigo; A.C. de Aguiar participou da análise dos dados e redação do artigo. 


\section{Abstract}

Senses of intimate violence: analysis of an anonymous telephone service database This paper aims to identify and interprete, in the resultant database of the registers of an Anonymous Telephone Service of support and advisement in the areas of rights and violence against women, the perception and the attribution of meanings of their experiences of intimate violence mainly in the light of contemporary Brazilian feminist literature. This text is aligned to a group of investigators who focused the attention in describing and thinking about the feminine representations about the violence, pointing out the non-universality of the feminine experience in relation to aggressions, valuing singular aspects of the attacked women. In the data analysis the meanings women give to their prolonged hesitations against the expressed desire to separate themselves from their abusive spouses are highlighted. The results support previous researchs on the complexity and morbidity of the phenomenon and also point to the need of the intersection of research fields in order the expansion of their understanding and more effective interventions.

Key words: Violence against woman; woman dials; gender relations; meanings of intimate violence. 